\title{
Fluorescent quantitative PCR of Mycobacterium tuberculosis for differentiating intestinal tuberculosis from Crohn's disease
}

\author{
B.Y. Fei ${ }^{1}$, H.X. Lv ${ }^{2}$ and W.H. Zheng ${ }^{1}$ \\ ${ }^{1}$ Department of Gastroenterology, Zhejiang Province People's Hospital, Hangzhou, Zhejiang Province, China \\ ${ }^{2}$ Department of Clinical Laboratory, Zhejiang Province People's Hospital, Hangzhou, Zhejiang Province, China
}

\begin{abstract}
Intestinal tuberculosis (ITB) and Crohn's disease (CD) are granulomatous disorders with similar clinical manifestations and pathological features that are often difficult to differentiate. This study evaluated the value of fluorescent quantitative polymerase chain reaction (FQ-PCR) for Mycobacterium tuberculosis (MTB) in fecal samples and biopsy specimens to differentiate ITB from CD. From June 2010 to March 2013, 86 consecutive patients (38 females and 48 males, median age 31.3 years) with provisional diagnoses of ITB and CD were recruited for the study. The patients' clinical, endoscopic, and histological features were monitored until the final definite diagnoses were made. DNA was extracted from $250 \mathrm{mg}$ fecal samples and biopsy tissues from each patient. The extracted DNA was amplified using FQ-PCR for the specific MTB sequence. A total of 29 ITB cases and 36 CD cases were included in the analysis. Perianal disease and longitudinal ulcers were significantly more common in the CD patients $(P<0.05)$, whereas night sweats, ascites, and circumferential ulcers were significantly more common in the ITB patients $(\mathrm{P}<0.05)$. Fecal FQ-PCR for MTB was positive in $24(82.8 \%)$ ITB patients and 3 (8.3\%) CD patients. Tissue PCR was positive for MTB in $16(55.2 \%)$ ITB patients and 2 (5.6\%) CD patients. Compared with tissue FQ-PCR, fecal FQ-PCR was more sensitive $\left(X^{2}=5.16, P=0.02\right)$. We conclude that $F Q-P C R$ for $M T B$ on fecal and tissue samples is a valuable assay for differentiating ITB from CD, and fecal FQ-PCR has greater sensitivity for ITB than tissue FQ-PCR.
\end{abstract}

Key words: Intestinal tuberculosis; Crohn's disease; Diagnosis; Fluorescent quantitative PCR; Mycobacterium tuberculosis

\section{Introduction}

Intestinal tuberculosis (ITB) and Crohn's disease (CD) are chronic granulomatous disorders (1) with similar clinical presentations and pathologies. Currently, the annual incidence of tuberculosis (TB) in China is approximately 1.3 million cases (second only to India) (2) and accounts for $14.3 \%$ of worldwide TB cases. The incidence of ITB, a common form of extrapulmonary TB, has increased in parallel with the overall resurgence of TB. In China, the prevalence of inflammatory bowel disease (IBD) has increased rapidly in recent years, mimicking its rapid growth in the developed world. The total number of IBD cases increased approximately 2.5 -fold over the previous decade, and there has been a 15.7-fold increase in the number of CD patients (3). Misdiagnosis of CD and ITB is common in developing countries (4), particularly China (5). In the case of ITB misdiagnosis, unnecessary anti-TB therapy poses a risk of toxicity and delays the treatment of CD. Conversely, treating ITB with steroids alone can lead to severe deterioration, or even death.

It is challenging to distinguish CD from ITB, particularly in highly endemic TB areas (6-8). A variety of clinical, endoscopic, and radiological criteria have been recommended to differentiate between the two conditions, but these criteria have demonstrated limitations (9-11). Some researchers have attempted to find new and specific differential diagnostic methods to distinguish between these conditions. T-SPOT.TB, an interferon-gamma release assay of whole blood, is a valuable assay for differentiating ITB from CD, particularly for the diagnostic exclusion of ITB based on its high specificity and negative predictive value (12-14). However, in highly endemic TB areas, such as China, where latent infection is widespread, 
a positive T-SPOT.TB result may not necessarily discriminate active TB from latent TB.

The TB polymerase chain reaction (PCR) assay is an interesting and promising approach. Amarapurkar et al. (15) reported that using TB PCR for biopsy specimens was a valuable method to differentiate ITB from CD. However, the positive rate of TB PCR was low $(21.6 \%)$ in ITB patients. If the sensitivity is improved, in situ PCR is potentially useful for differentiating between ITB and CD (16). Ramadass et al. (17) have shown that, when combined with an acid-fast bacilli (AFB) culture, conventional fecal PCR, targeting the IS6110 sequence of the Mycobacterium tuberculosis (MTB) genome, can distinguish between ITB and CD. It remains to be determined whether the ITB diagnostic sensitivity of the test will increase with increasing refinement of PCR techniques.

In the present study, we evaluated the usefulness of fluorescent quantitative (FQ)-PCR in fecal samples and biopsy specimens as a means of differentiating between ITB and CD.

\section{Material and Methods}

From June 2010 to March 2013, 86 consecutive patients ( 38 females and 48 males, median age 31.3 years) with provisional diagnoses of ITB and CD were recruited into the study. The patients who had received treatment for TB in the 3 months prior to the sample collection were excluded. A single stool sample was collected from each patient and stored at $-50^{\circ} \mathrm{C}$ prior to processing. All patients had undergone colonoscopies. Multiple biopsy specimens were obtained from affected areas and stored at $-50^{\circ} \mathrm{C}$ prior to processing. The patients were investigated following routine clinical, endoscopic, and histological protocols and followed up after the therapy. All research involving human participants was approved by the Zhejiang Province People's Hospital. Written informed consent was obtained from the participants, and all clinical investigations were conducted according to the principles expressed in the Declaration of Helsinki.

The ITB diagnosis was established if at least one of the following criteria was met: 1) histological evidence of a caseating granuloma, 2) histological demonstration of AFB, 3) intestinal granulomatous inflammation accompanied by histologically or microbiologically confirmed extraintestinal TB, and 4) a positive MTB culture. The $\mathrm{CD}$ diagnosis was based on well-established clinical, endoscopic, radiological, and histological parameters in accordance with the criteria in the literature $(18,19)$. In patients for whom the differentiation between ITB and CD was uncertain, anti-TB therapy was attempted for 2-3 months, and the final diagnosis was made based on the clinical and endoscopic response to the anti-TB therapy. The clinical response was determined by the loss of subjective symptoms. The endoscopic response was determined by the disappearance of ulcerations.
DNA was extracted from $250 \mathrm{mg}$ fecal and biopsy tissues using a QiaAMP Stool DNA mini kit and QiaAMP DNA micro kit (Qiagen, Germany), respectively. The specific sequence was amplified using an MTB DNA (PCRfluorescence) diagnostic kit with Roche LightCycler PCR amplification (Roche, Germany). The FQ-PCR mixture was prepared in a total volume of $20 \mu \mathrm{L}$, which contained $2-\mu \mathrm{L}$ DNA sample. FQ-PCR was performed under the following conditions: initial activation at $93^{\circ} \mathrm{C}$ for $2 \mathrm{~min}$, followed by 40 cycles at $93^{\circ} \mathrm{C}$ for $5 \mathrm{~s}, 57^{\circ} \mathrm{C}$ for $45 \mathrm{~s}$, and, finally, extension at $72^{\circ} \mathrm{C}$ for $1 \mathrm{~s}$. Amplifications were performed and results analyzed according to the manufacturer's instructions.

\section{Statistical analysis}

The differences in proportions were analyzed using the Fisher exact test. The Student $t$-test was used to compare mean values of the appropriate parameters in the two groups. A value of $\mathrm{P}<0.05$ was considered to be statistically significant.

\section{Results}

Eighty-six patients were initially recruited for the collection of fecal samples and biopsy tissues. Twentyone patients were excluded from the study because of diagnoses other than ITB or CD. A total of 29 ITB cases and 36 CD cases were included in the analysis.

The clinical, endoscopic, and histological features differentiating between ITB and CD are demonstrated in Table 1. Perianal disease and longitudinal ulcer were significantly more common in the CD patients than in the ITB patients, whereas night sweats, ascites and circumferential ulcers were significantly more common in the ITB patients than in the $C D$ patients. Stricture was more frequently observed in the $C D$ patients than in the ITB patients; however, the difference did not reach statistical significance.

The results of fecal TB FQ-PCR, tissue TB FQ-PCR, and the tuberculin skin test (TST) are shown in Table 2. Fecal TB FQ-PCR was positive in 24 (82.8\%) ITB patients and $3(8.3 \%)$ CD patients. Tissue FQ-PCR was positive in $16(55.2 \%)$ ITB patients and $2(5.6 \%)$ CD patients. Compared to tissue TB FQ-PCR, fecal TB FQ-PCR had greater sensitivity $\left(X^{2}=5.16, P=0.02\right)$. Tissue TB FQPCR had a sensitivity similar to that of the TST.

The overall sensitivity, specificity, positive predictive value (PPV), and negative predictive value (NPV) of fecal TB FQ-PCR, tissue TB FQ-PCR, and TST are listed in Table 3. Fecal TB FQ-PCR had greater sensitivity and NPV than tissue FQ-PCR. Tissue TB FQ-PCR had greater specificity and PPV than the TST.

\section{Discussion}

The symptoms and signs of ITB are nonspecific and share many similarities with $C D$. There are many 
Table 1. The differentiating clinical, endoscopic, and histological features of patients with intestinal tuberculosis (ITB) and Crohn's disease (CD).

\begin{tabular}{lcc}
\hline & ITB $(\mathrm{n}=29)$ & CD $(\mathrm{n}=36)$ \\
\hline Clinical presentation & & \\
Age, years (means \pm SD) & $30.3 \pm 11.6$ & $31.7 \pm 12.5$ \\
Gender (male:female) & $14: 15$ & $22: 14$ \\
Abdominal pain & $23(79.3 \%)$ & $33(91.7 \%)$ \\
Diarrhea & $19(65.5 \%)$ & $27(75.0 \%)$ \\
Hematochezia & $6(20.7 \%)$ & $12(33.3 \%)$ \\
Ascites & $8(27.6 \%)$ & $0(0.00 \%)^{*}$ \\
Fever & $17(58.6 \%)$ & $18(50.0 \%)$ \\
Night sweats & $16(55.2 \%)$ & $8(22.2 \%)^{*}$ \\
Perianal disease & $1(3.4 \%)$ & $8(22.2 \%)^{*}$ \\
Endoscopic features & & \\
Longitudinal ulcer & $4(13.8 \%)$ & $13(36.1 \%)^{*}$ \\
Circumferential ulcer & $18(62.1 \%)$ & $6(16.7 \%)^{*}$ \\
Aphthous ulcers & $3(10.3 \%)$ & $9(25.0 \%)$ \\
Cobblestone appearance & $5(17.2 \%)$ & $12(33.3 \%)$ \\
Pseudo-polyps & $8(27.6 \%)$ & $16(44.4 \%)$ \\
Stricture & $4(13.8 \%)$ & $12(33.3 \%)^{*}$ \\
Histological features & & \\
Caseating granulomas & $3(10.3 \%)$ & $0(0.00 \%)$ \\
Non-caseating granulomas & $9(31.0 \%)$ & $5(13.9 \%)$ \\
Lymphocyte aggregation & $12(41.4 \%)$ & $12(33.3 \%)$ \\
\hline
\end{tabular}

Data are reported as number with percent in parentheses. ${ }^{*} \mathrm{P}<0.05$, compared to ITB (Fisher exact test).

proposed clinical, radiological, endoscopic, and histological features that distinguish ITB from $C D$, including a prolonged illness, diarrhea, hematochezia, weight loss, extraintestinal manifestations, fever, ascites, deep linear ulcers, cobble-stone appearance, involvement of the sigmoid colon, coexisting pulmonary lesions, and abdominal lymphadenopathy, etc. (20-22). In the present study, perianal disease and longitudinal ulcers were more common in the $C D$ patients, whereas night sweats, ascites, and circumferential ulcers were more common in the ITB patients. In general, positive findings in the histology and microbiology of ITB and CD are unsatisfactory (6), and a comprehensive analysis of the clinical, endoscopic, and histological disease features may help to confirm the diagnosis. Li et al. (23) reported that a combination of clinical and endoscopic parameters leads to elevated accuracy and specificity in differentiating $C D$ from ITB. Further research involving a large sample and multicenter cooperation is needed.

The most reliable differentiation method is finding evidence of MTB in intestinal tissues. Unfortunately, AFB staining has low sensitivity. In addition, the biopsy culture for MTB is time consuming (3-8 weeks), and the results are frequently negative (accuracy ranging from 25 to $35 \%$ ) (11). The PCR assay provides a rapid and sensitive approach, and PCR techniques are being refined to increase their diagnostic sensitivity. FQ-PCR has become a potentially powerful alternative in microbiological diagnosis because of its simplicity, rapidity, reproducibility, and accuracy. Hillemann et al. (24) have shown that the real-time PCR assay exhibits a higher sensitivity $(66.7 \%)$ for detecting MTB complex DNA than an alternative in-house IS6110 PCR (33.3\%) in formalin-fixed, paraffin-embedded tissues.

The PCR detection of mycobacteria in histopathological specimens was introduced as a rapid and useful technique for diagnosing pulmonary and extrapulmonary TB $(25,26)$. Gan et al. (27) reported a $64.1 \%(25 / 39)$ positivity rate from PCR in 39 ITB biopsy specimens, but zero positivity from PCR in $30 \mathrm{CD}$ specimens. A study using in situ PCR indicated the presence of MTB DNA in 6 of 20 mucosal biopsy specimens from patients with ITB and in 1 of 20 biopsy specimens from patients with CD (16). In the present study, PCR detection of mycobacteria in biopsy specimens was positive in $16(55.2 \%)$ ITB cases and $2(5.6 \%)$ CD cases. Thus, tissue FQ-PCR is potentially useful to differentiate between ITB and CD. Compared to fecal FQ-PCR, tissue FQ-PCR has a lower sensitivity. In this study, all tissue samples were obtained from endoscopic biopsies, and the tissue samples were superficial and small in number. MTB would not be distributed evenly in the tissue. Low numbers of extracted MTB DNA in mucosal biopsy specimens could be responsible for the false-negative results of tissue PCR. In the study, although the tissue TB FQ-PCR assay had a sensitivity similar to the TST, tissue TB FQ-PCR had higher specificity and PPV than the TST. This finding suggests that tissue TB FQ-PCR has more clinical value than the TST.

Table 2. Results of fecal FQ-PCR, tissue FQ-PCR and TST for Mycobacterium tuberculosis in the patient groups.

\begin{tabular}{lccc}
\hline & Intestinal TB $(\%)$ & Crohn's disease $(\%)$ & $P$ \\
\hline Total number of patients & 29 & 36 & \\
Fecal FQ-PCR positive & $24(82.8 \%)$ & $3(8.3 \%)$ & 0.00 \\
Tissue FQ-PCR positive & $16(55.2 \%)$ & $2(5.6 \%)$ & 0.00 \\
TST positive & $17(58.6 \%)$ & $11(30.6 \%)$ & 0.02 \\
\hline
\end{tabular}

Data are reported as number with percent in parentheses. FQ-PCR: fluorescent quantitative polymerase chain reaction; TST: tuberculin skin test. The Fisher exact test was used for statistical analyses. 
Table 3. Clinical evaluation of fecal FQ-PCR, tissue FQ-PCR and TST.

\begin{tabular}{lllll}
\hline & Sensitivity $(95 \% \mathrm{Cl})$ & Specificity $(95 \% \mathrm{Cl})$ & PPV $(95 \% \mathrm{Cl})$ & $\mathrm{NPV}(95 \% \mathrm{Cl})$ \\
\hline Fecal FQ-PCR & $82.8 \%(65.45-92.4)$ & $91.7 \%(78.2-97.1)$ & $88.9 \%(71.9-96.2)$ & $86.8 \%(72.7-94.3)$ \\
Tissue FQ-PCR & $55.2 \%(37.6-71.6)$ & $94.4 \%(81.9-98.5)$ & $88.9 \%(67.2-96.9)$ & $72.3 \%(58.2-83.1)$ \\
TST & $58.6 \%(40.7-74.5)$ & $69.4 \%(53.0-83.1)$ & $60.7 \%(42.4-76.5)$ & $67.6 \%(51.38-80.45)$ \\
\hline
\end{tabular}

FQ-PCR: fluorescent quantitative polymerase chain reaction; TST: tuberculin skin test; Cl: confidence interval; PPV: positive predictive value; NPV: negative predictive value.

Unlike an endoscopic biopsy, fecal PCR is noninvasive and less subject to sampling errors. Fecal PCR can theoretically detect mycobacterial DNA shed from anywhere along the length of the gastrointestinal tract. Balamurugan et al. (28) reported that the sensitivity, specificity, PPV, and NPV of PCR detection of MTB in fecal samples of ITB patients were $88.8,100,100$, and $93.7 \%$, respectively. Further studies have shown that fecal PCR combined with AFB culture provides a good test to distinguish between ITB and $C D$, with a sensitivity of $95 \%$ and specificity of $88 \%$ (17). In the present study, fecal FQ-PCR was positive in 24 $(82.8 \%)$ ITB cases and $3(8.3 \%)$ CD cases. The sensitivity, specificity, PPV, and NPV of fecal FQ-PCR were 82.8, 91.7, 88.9 , and $86.8 \%$, respectively. These results suggest that fecal FQ-PCR is a valuable assay for differentiating ITB from CD. However, we did not find that fecal FQ-PCR detection of MTB was superior to regular PCR (28).

The results showed that fecal PCR was positive in

\section{References}

1. Kirsch R, Pentecost M, Hall PM, Epstein DP, Watermeyer G, Friederich PW. Role of colonoscopic biopsy in distinguishing between Crohn's disease and intestinal tuberculosis. J Clin Pathol 2006; 59: 840-844, doi: 10.1136/ jcp.2005.032383.

2. National Technic Steering Group of the Epidemiological Sampling Survey for Tuberculosis, Duanmu H. [Report on Fourth National Epidemiological Sampling Survey of Tuberculosis]. Zhonghua Jie He He Hu Xi Za Zhi 2002; 25: 3-7.

3. Ouyang $Q$, Xue LY. Inflammatory bowel disease in the $21^{\text {st }}$ century in China: turning challenges into opportunities. J Dig Dis 2012; 13: 195-199, doi: 10.1111/j.1751-2980.2012.00579.x.

4. Patel N, Amarapurkar D, Agal S, Baijal R, Kulshrestha P, Pramanik S, et al. Gastrointestinal luminal tuberculosis: establishing the diagnosis. J Gastroenterol Hepatol 2004; 19: 1240-1246, doi: 10.1111/j.1440-1746.2004.03485.x.

5. Chang YY, Ouyang Q, Hu RW. An analysis of misdiagnosed Crohn's disease in China. Chin J Dig Endosc 2005; 22: 372-375.

6. Almadi MA, Ghosh S, Aljebreen AM. Differentiating intestinal tuberculosis from Crohn's disease: a diagnostic challenge. Am J Gastroenterol 2009; 104: 1003-1012, doi: 10.1038/ajg.2008.162.

7. Rolo R, Campainha S, Duarte R. Crohn's disease and intestinal tuberculosis: a clinical challenge. Rev Port Pneumol three $(8.3 \%) \mathrm{CD}$ cases and tissue PCR was positive in two $(5.6 \%)$ CD cases. The presence of MTB may be an epiphenomenon, considering its high prevalence in the general population and incidental entry into the inflamed bowel from contaminated food or water. Latent TB infection may exist in patients with $C D$, which may be unmasked by infliximab therapy $(29,30)$. A series of studies using genetic and serological techniques now purport to have identified mycobacteria at a higher prevalence in Crohn's patients than in control subjects (31-33). However, whether mycobacteria in CD act as a trigger for the abnormal inflammatory response remains an issue for further research.

\section{Acknowledgments}

Research supported by the Zhejiang Provincial Science Foundation of Medicine and Health (\#2010KYA020).

2012; 18: 205-206, doi: 10.1016/j.rppneu.2012.02.006

8. Pulimood AB, Amarapurkar DN, Ghoshal U, Phillip M, Pai CG, Reddy DN, et al. Differentiation of Crohn's disease from intestinal tuberculosis in India in 2010. World J Gastroenterol 2011; 17: 433-443, doi: 10.3748/wjg.v17.i4.433.

9. Navaneethan U, Cherian JV, Prabhu R, Venkataraman J. Distinguishing tuberculosis and Crohn's disease in developing countries: how certain can you be of the diagnosis? Saudi J Gastroenterol 2009; 15: 142-144, doi: 10.4103/1319-3767. 49012.

10. Sinhasan SP, Puranik RB, Kulkarni MH. Abdominal tuberculosis may masquerade many diseases. Saudi $J$ Gastroenterol 2011; 17: 110-113, doi: 10.4103/13193767.77239

11. Amarapurkar DN, Patel ND, Rane PS. Diagnosis of Crohn's disease in India where tuberculosis is widely prevalent. World J Gastroenterol 2008; 14: 741-746, doi: 10.3748/ wjg.14.741.

12. Kim BJ, Choi YS, Jang BI, Park YS, Kim WH, Kim YS, et al. Prospective evaluation of the clinical utility of interferongamma assay in the differential diagnosis of intestinal tuberculosis and Crohn's disease. Inflamm Bowel Dis 2011; 17: 1308-1313, doi: 10.1002/ibd.21490.

13. Li Y, Zhang LF, Liu XQ, Wang L, Wang $X$, Wang J, et al. The role of in vitro interferongamma-release assay in differentiating intestinal tuberculosis from Crohn's disease 
in China. J Crohns Colitis 2012; 6: 317-323, doi: 10.1016/ j.crohns.2011.09.002.

14. Lei Y, Yi FM, Zhao J, Luckheeram RV, Huang S, Chen M, et al. Utility of in vitro interferon-gamma release assay in differential diagnosis between intestinal tuberculosis and Crohn's disease. J Dig Dis 2013; 14: 68-75, doi: 10.1111/ 1751-2980.12017.

15. Amarapurkar DN, Patel ND, Amarapurkar AD, Agal S, Baigal R, Gupte P. Tissue polymerase chain reaction in diagnosis of intestinal tuberculosis and Crohn's disease. $J$ Assoc Physicians India 2004; 52: 863-867.

16. Pulimood AB, Peter S, Rook GW, Donoghue HD. In situ PCR for Mycobacterium tuberculosis in endoscopic mucosal biopsy specimens of intestinal tuberculosis and Crohn disease. Am J Clin Pathol 2008; 129: 846-851, doi: 10. 1309/DKKECWQWMG4J23E3.

17. Ramadass B, Chittaranjan S, Subramanian V, Ramakrishna BS. Fecal polymerase chain reaction for Mycobacterium tuberculosis IS6110 to distinguish Crohn's disease from intestinal tuberculosis. Indian J Gastroenterol 2010; 29: 152-156, doi: 10.1007/s12664-010-0022-3.

18. Ouyang Q, Tandon R, Goh KL, Pan GZ, Fock KM, Fiocchi C, et al. Management consensus of inflammatory bowel disease for the Asia-Pacific region. J Gastroenterol Hepatol 2006; 21: 1772-1782, doi: 10.1111/j.1440-1746.2006.04674.x.

19. Stange EF, Travis SP, Vermeire S, Beglinger C, Kupcinkas $\mathrm{L}$, Geboes K, et al. European evidence based consensus on the diagnosis and management of Crohn's disease: definitions and diagnosis. Gut 2006; 55 (Suppl 1): i1-i15, doi: 10.1136/gut.2005.081950a.

20. Yu H, Liu Y, Wang Y, Peng L, Li A, Zhang Y. Clinical, endoscopic and histological differentiations between Crohn's disease and intestinal tuberculosis. Digestion 2012; 85: 202-209, doi: 10.1159/000335431.

21. Dutta AK, Sahu MK, Gangadharan SK, Chacko A. Distinguishing Crohn's disease from intestinal tuberculosis a prospective study. Trop Gastroenterol 2011; 32: 204-209.

22. Makharia GK, Srivastava S, Das P, Goswami P, Singh U, Tripathi $M$, et al. Clinical, endoscopic, and histological differentiations between Crohn's disease and intestinal tuberculosis. Am J Gastroenterol 2010; 105: 642-651, doi: 10.1038/ajg.2009.585.

23. Li X, Liu X, Zou Y, Ouyang C, Wu X, Zhou M, et al. Predictors of clinical and endoscopic findings in differentiating Crohn's disease from intestinal tuberculosis. Dig Dis Sci 2011; 56: 188-196, doi: 10.1007/s10620-010-1231-4.
24. Hillemann D, Galle J, Vollmer E, Richter E. Real-time PCR assay for improved detection of Mycobacterium tuberculosis complex in paraffin-embedded tissues. Int J Tuberc Lung Dis 2006; 10: 340-342.

25. Lira LA, Santos FC, Carvalho MS, Montenegro RA, Lima JF, Schindler HC, et al. Evaluation of a IS6110-Taqman real-time PCR assay to detect Mycobacterium tuberculosis in sputum samples of patients with pulmonary TB. J Appl Microbiol 2013; 114: 1103-1108, doi: 10.1111/jam.12119.

26. Takahashi T, Tamura M, Takasu T. The PCR-based diagnosis of central nervous system tuberculosis: up to date. Tuberc Res Treat 2012; 2012: 831292.

27. Gan HT, Chen $Y Q$, Ouyang $Q$, Bu H, Yang XY. Differentiation between intestinal tuberculosis and Crohn's disease in endoscopic biopsy specimens by polymerase chain reaction. Am J Gastroenterol 2002; 97: 1446-1451, doi: 10.1111/j.1572-0241.2002.05686.x.

28. Balamurugan R, Venkataraman S, John KR, Ramakrishna BS. PCR amplification of the IS6110 insertion element of Mycobacterium tuberculosis in fecal samples from patients with intestinal tuberculosis. J Clin Microbiol 2006; 44: 18841886, doi: 10.1128/JCM.44.5.1884-1886.2006.

29. Papa A, Mocci G, Bonizzi M, Felice C, Andrisani G, De Vitis I, et al. Use of infliximab in particular clinical settings: management based on current evidence. Am J Gastroenterol 2009; 104: 1575-1586, doi: 10.1038/ajg.2009.162.

30. Garcia-Vidal C, Rodriguez-Fernandez S, Teijon S, Esteve M, Rodriguez-Carballeira M, Lacasa JM, et al. Risk factors for opportunistic infections in infliximab-treated patients: the importance of screening in prevention. Eur J Clin Microbiol Infect Dis 2009; 28: 331-337, doi: 10.1007/s10096-0080628-x.

31. Lalande JD, Behr MA. Mycobacteria in Crohn's disease: how innate immune deficiency may result in chronic inflammation. Expert Rev Clin Immunol 2010; 6: 633-641, doi: 10.1586/eci.10.29.

32. Chiodini RJ, Chamberlin WM, Sarosiek J, McCallum RW. Crohn's disease and the mycobacterioses: a quarter century later. Causation or simple association? Crit Rev Microbiol 2012; 38: 52-93, doi: 10.3109/1040841X.2011.638273.

33. Biet F, Gendt L, Anton E, Ballot E, Hugot JP, Johanet C. Serum antibodies to Mycobacterium avium subspecies paratuberculosis combined with anti-Saccharomyces cerevisiae antibodies in Crohn's disease patients: prevalence and diagnostic role. Dig Dis Sci 2011; 56: 1794-1800, doi: 10.1007/s10620-010-1523-8. 